\title{
EL MISTERIO FEMENINO EN LOS PERROS DE ELENA GARRO
}

Los perros, pieza en un acto de Elena Garro, presenta el rapto de Ursula, una niña de doce años, hija de una mujer pobre. La desventura de Ursula repite en todos sus pormenores la que sufrió su madre, Manuela, en su propia niñez. Estos raptos y los detalles que los circundan muestran una marcada semejanza con el mito clásico de Deméter y Perséfone, madre e hija, ambas víctimas de la misma violencia, ambas diosas del grano cereal, de la tierra y de la luna.

La pieza de Elena Garro alude también, de modo indirecto, a los ritos aztecas de la fertilidad, en particular a los de la diosa del grano cereal, Xilonen, cuyo nombre quiere decir mazorca tierna y fresca, según el padre Durán, y a su madre Chicomecóatl, diosa de la tierra, en cuyo honor se sacrificaba a una niña de doce años.

Antes de referirnos al drama Los perros para ver la forma en que estas características mitológicas asoman en el texto, creemos oportuno detenernos un poco en el valor de dichos mitos en su sentido profundo. Para el mundo antiguo, la Core o Doncella Perséfone ejemplificaba el ser femenino en su estado incipiente. El culto a Core y a Deméter se celebraba en Eleusis, y aunque los hombres participaban, los misterios de Eleusis tenían un alcance mucho más grande para la psique femenina. Desde un punto de vista elemental, el rapto de Perséfone por Hades, el dios del infierno, seguido de la reunión entre madre e hija después de una larga búsqueda, constituía un rito de sacrificio de muerte y de resurrección en que todos los concurrentes, hombres y mujeres, hallaban la vida en la muerte.

Sin embargo, otra dimensión se presentaba en torno a la pareja Deméter-Perséfone como figuras ejemplares. La doncella y la matrona se completaban, y así representaban a la mujer total. Eran, en realidad, dos aspectos de una misma diosa, en cuanto cada una se transformaba continuamente en la otra: la una daba a luz y llegaba a ser madre; la otra renacía en su hija y volvía a ser doncella. El culto de esta pareja pri- 
mordial servía para ensanchar la conciencia femenina, extendiéndola hacia adelante en su hija y hacia atrás en su madre. Intimaba la existencia de una personalidad femenina eterna que abarcaba todas las potencialidades del sexo. Por los lazos que sentía tener con esta entidad inmortal, la mujer descubría el lugar que le correspondía entre las generaciones y el sentido de su vida. La iniciada a los misterios de Eleusis se sentía rescatada de la soledad e investida de su propia identidad ${ }^{1}$.

En la obra de Elena Garro, la presencia del mito griego ilumina la triste historia de las campesinas desamparadas con matices extraterrestres y las eleva al rango de prototipos. Aparte del tema general de los raptos, otros parecidos con Deméter y Perséfone se ven reflejados en la pieza. Cuentan que el rapto de Perséfone ocurrió al abrirse un agujero a sus pies, que Hades surgió y se la llevó a los infiernos. El pueblo de Ursula está lleno de agujeros que la asustan, dice ella; y Jerónimo, quien la quiere robar, tiene vapores que le salen de los ojos como al dios infer$\mathrm{nal}^{2}$. Se habla de los demonios en relación con él, y su nombre, Jerónimo, quiere decir «el que lleva un nombre sagrado», significación adecuada al dios del inframundo.

La identidad entre las vidas de Ursula y de Manuela se prolonga hasta incluir a la abuela. Esta anduvo buscando a su hija durante siete años (el siete es el número mítico del renacer), como Manuela habrá de buscar a Ursula, y como Deméter buscó a Perséfone, ya que la búsqueda es una parte principal del drama eleusiano. La desaparición de Perséfone corresponde al invierno, en el sentido agrario, y en el sentido lunar, su ausencia corresponde a la fase del novilunio, ya que la pareja DeméterPerséfone tiene parentesco con la luna. Efectivamente, Artemis (o Diana), diosa lunar, era una variante de ellas; su emblema era el oso. El nombre de Ursula quiere decir Osa. Ursula comenta que con su traje nuevo se parecerá a un espejo (p. 70). La luna se compara a menudo con un espejo. Otro símbolo de Artemis en su forma negativa era el perro: a ella se sacrificaba este animal. En la pieza, los que vienen a robar a la niña mutilan a sus perros: les cortan las patas, que es una especie de sacrificio infligido al animal. Luego echan un sarape sobre la cabeza de Ursula y se la 1levan. En Eleusis, los que ingresaban en los misterios se velaban la cabeza para significar que en unión con Perséfone se en-

${ }^{1}$ Carl G. Jung and Carl Kerényi, Essays on a Science of Mythology: The Myths of the Divine Child and the Divine Maiden, trad. de R. F. C. Hull (1941; rpt. New York: Harper Torchbooks, 1963), p. 162.

${ }^{2}$ Elena Garro, Los perros, en 12 obras en un acto, prólogo de Wilberto Cantón (México: Ecuador 000'0”, 1967), pp. 71-72. Todas las citas provienen de esta edición. 
tregaban a la muerte, pues la violación de la diosa se veía como un autosacrificio ${ }^{3}$. El nombre de Manuela significa «diosa con nosotros»; su apellido, Albear, y el nombre de su madre, Albina, evocan lo blanco y parecen confirmar su carácter lunar.

La fiesta que se celebra en la pieza es la de San Miguel, a fines de septiembre. Los misterios de Eleusis se celebraban también en estas fechas, así como las fiestas de las diosas aztecas Chicomecóatl y su hija Xilonen, diosas del maíz. Según el padre Durán, era la fiesta de los elotes, durante la cual se hacían tortillas de maíz fresco. Manuela está palmeando tortillas durante todo el acto, pues es así como se gana la vida. Los elotes se cuecen en un bote que atiende Ursula, y al final, después de que ésta ha sido raptada, la madre atraviesa la choza con el tompiate de tortillas y lo deposita en el lugar preciso que había ocupado Ursula, como para subrayar la conexión entre ella y el maíz. Hay otro indicio que identifica a estas mujeres con el maíz: la abuela murió de golpes, con «los dientes rotos, saliéndosele de la boca» (p. 80), o sea, como quien desgrana, a golpes, la mazorca seca.

Chicomecóatl quiere decir «culebra de siete cabezas», informa el padre Durán, y era la diosa del hambre, así como del grano. Manuela habla de tener «las siete bocas del hambre en las enaguas» (p. 69). El raptor de Ursula, Jerónimo, quisiera arrancarle la piel (p. 75); para la fiesta de la diosa azteca se desollaba a una niña de doce años, que encarnaba a Xilonen. Quizá el traje rosa que Ursula deja atrás, y que su madre ya sola recoge como hipnotizada, represente aquel pellejo; parece que arrancar el pellejo a las víctimas equivalía, entre otras cosas, a quitar las hojas a la mazorca.

Me parece que estos detalles, entre los muchos que hay en el texto, bastan para establecer que Elena Garro ha encargado a sus dos protagonistas el papel de evocar a la vez las deidades aztecas del alimento y sus equivalentes del Olimpo griego. Son, además, en el plano actual, mujeres elementales que encarnan la «atroz condición femenina», expresión de Octavio Paz relativa al machismo ${ }^{4}$. Podríamos concluir que la autora, al yuxtaponer estos mitos y ritos femeninos, quiso señalar cómo la mujer, guiada por un feliz instinto, ha logrado y mantenido su identidad femenina, sean las que fueren sus condiciones de existencia.

Pero hay más. Los perros es en parte una amplificación de lo que refiere Octavio Paz en El laberinto de la soledad con respecto a las rela-

\footnotetext{
${ }^{3}$ Essays, p. 139.

${ }^{4}$ Octavio Paz, El laberinto de la soledad (1950; rpt. México: Fondo de Cultura Económica, 1969), p. 77.
} 
ciones entre los sexos. El primo de Ursula le advierte que la van a raptar "para que nunca llegues a ser mujer lucida y temida de los hombres» (p. 75). La idea de que el hombre tema a la mujer trae a la memoria la tesis de Paz de que el machismo no es otra cosa que una adolescencia prolongada, debido a que el macho es incapaz de establecer una relación personalística, de igual a igual, con la mujer. El machista desprecia a la mujer al mismo tiempo que la idealiza. Es, por una parte, la Chingada, y por otra, la madre virgen: Doña Marina y la Guadalupe. La mujer queda como entidad transpersonal y arquetípica, y el macho es dominado por este arquetipo. Psicológicamente, la situación se debe a que el macho no ha sabido enfrentarse con su propia feminidad, no se ha abierto al mundo de los sentimientos, al Eros, que para él resulta totalmente otro y ajeno. «El ideal de la 'hombría' consiste en no 'rajarse' nunca», dice $\mathrm{Paz}^{5}$. En realidad, «abrirse» sería olvidarse de sí mismo, superarse, dar el salto mortal hacia la comunión, que es el fin y la meta de la vida. Pero el macho permanece paralizado ante lo femenino. Quizá eso explique la frase singular del primo de Ursula, el cual añade: «E1 hombre que teme a la mujer abunda, es malo y la rompe desde antes de que sea mujer» (p. 76).

Esta actitud inconsciente y, por tanto, involuntaria tiene su correspondencia en la cultura azteca, como verifican los mitos, puesto que los mitos revelan la condición de los hombres. Las diosas se mostraban temibles y bastante monstruosas; aun la doncella Xilonen no era nada idílica. Sin embargo, el culto a los dioses solares era un intento de superar aquel miedo. Un ejemplo de ello está a mano: el desollamiento a que alude nuestra pieza cuando se dice que Jerónimo quiere arrancar la piel a Ursula. Según algunos psicólogos, el desollar a la muchacha que encarnaba a Xilonen-Chicomecóatl y el revestirse como oficiante del pellejo equivale a sacrificar el principio femenino, apoderarse de su cualidad de tal y transformarla en potencia masculina, como el feto masculino se forma de la sustancia femenina. Equivalía a introducirse dentro de la diosa y, gracias al carácter transformativo de lo femenino, hacerse su hijo, es decir, semejante al dios del sol y del maíz, Huitzilopochtli ${ }^{6}$.

Por otra parte, el hombre que participaba en los misterios de Eleusis no se identificaba con Hades, sino con Deméter y con las emociones del drama; es decir, con su propia feminidad. Era una experiencia del Eros, no del Logos. En ambos casos, en Tenochtitlán como en Eleusis, el hom-

${ }^{5}$ Laberinto, p. 26.

' Erich Neumann, The Great Mother: An Analysis of the Archetype (Princeton: Princeton University Press, 1955), p. 195. 
bre se dejaba guiar por instintos positivos que lo movían a desarrollar su personalidad.

Por último, invirtiendo la dirección del enfoque, hemos de observar que el aparente pesimismo de la pieza Los perros se debe a que Elena Garro ha querido personificar el grano cereal en sus personajes, como lo hicieron los pueblos de antaño con sus diosas. Por su misma naturaleza, el grano ha de ser violado, derribado, golpeado y triturado. Así es que la repetición agobiante de las aflicciones de Manuela y Ursula tiene su finalidad, y sacamos la consecuencia de que el valor positivo de la pieza reside en que las peripecias están proyectadas a la esfera del mito, cuya función es canalizar los esfuerzos de la mujer y del hombre hacia una superación de sí mismos.

University of New Hampshire. 
